\title{
"Optics 4 every1", the hands-on optics outreach program of the Universidad Autonoma de Nuevo Leon
}

Perla Viera-González, Guillermo Sánchez-Guerrero

Perla M. Viera-González, Guillermo E. Sánchez-Guerrero, "'Optics 4 every1", the hands-on optics outreach program of the Universidad Autonoma de Nuevo Leon," Proc. SPIE 9946, Optics Education and Outreach IV, 994615 (27 September 2016); doi: 10.1117/12.2238070

SPIE Event: SPIE Optical Engineering + Applications, 2016, San Diego, California, United States 


\title{
"Optics 4 every1", the hands-on Optics outreach program of the Universidad Autonoma de Nuevo Leon
}

\author{
Perla M.Viera-González and Guillermo E. Sánchez-Guerrero \\ Facultad de Ciencias Físico Matemáticas, Universidad Autónoma de Nuevo León, Av. \\ Universidad S/N Ciudad Univertaria, 66455, San Nicolás de los Garza, México
}

\begin{abstract}
The Fisica Pato2 (Physics 4 every1) outreach group started as a need of hands-on activities and active Science demonstrations in the education for kids, teenagers and basic education teachers in Nuevo León maintaining a main objective of spread the word about the importance of Optics and Photonics; for accomplish this objective, since November 2013 several outreach events are organized every year by the group. The program Optics 4 every1 is supported by the Facultad de Ciencias Fisico Matematicas of the Universidad Autonoma de Nuevo Leon and the International Society for Optics and Photonics and consist in quick hands-on activities and Optics demonstrations designed for teach basic optical phenomena related with light and its application in everyday life. During 2015, with the purpose of celebrate the International Year of Light 2015, the outreach group was involved in 13 different events and reached more than 8,000 people. The present work explains the activities done and the outcome obtained with this program.
\end{abstract}

Keywords: optics outreach activities, International Year of Light, hands-on activities, STEM, science learning

\section{INTRODUCTION}

Currently, in correspondence with the accelerated scientific and technological development, the education not only is about how children and youth learn Science as the only outcome pursued by the process of teaching, indeed, it is clearly necessary to understand the meaning of learning Science as part of human knowledge, relate its branches not isolate them and develop the potential of all students. ${ }^{1}$ In this regard, the International Year of Light 2015 (IYL2015), provided a cross-disciplinary educational and outreach project where the program Optics 4 every 1 is supported.

\subsection{Local Teaching of Science, Mexico}

In the later years, the teaching of sciences has become a part of Nuevo León teachers interest, in consequence, Universities and local museums generated programs to fulfill this interest. A probable origin of this interest, can be, perhaps, that local teachers do not make use of experimentation to link theory and concepts and use these programs to meet this need. Moreover, the Optics 4 every1 outreach program follows the Active Learning in Optics and Photonics (ALOP) philosophy of fostering modern hands-on learning techniques ${ }^{2}$ and encourage the experimentation in schools.

\subsection{Optics 4 every1 outreach program}

One of the IYL2015 objectives is education and outreach, in this regard, the Optics 4 every1 is a program focused in the celebration of the IYL2015 with outreach activities to spread the word of Science and the celebration. This program was created at Facultad de Ciencias Fisico Matematicas (FCFM) and supported by the International Society for Optics and Photonics (SPIE).

The program events consisted in activities to teach certain science topics, including classical physics, geometrical and physical optics. Each event must contain at least 2 topics and relate them with hands-on experiments

Further author information: (Send correspondence to P.V.G.)

P.V.G.: E-mail: marlene.viera.gzz@gmail.com

G.S.G.: E-mail: guillermoesanchez@gmail.com

Optics Education and Outreach IV, edited by G. Groot Gregory, Proc. of SPIE Vol. 9946, 994615

(C) 2016 SPIE · CCC code: $0277-786 \mathrm{X} / 16 / \$ 18 \cdot$ doi: $10.1117 / 12.2238070$

Proc. of SPIE Vol. $9946994615-1$ 
or demonstrations. The characteristics of the hands-on activities are: low-cost and locally-available materials and homemade. In demonstrations and hands-on activities, the time is a key factor, usually, per event, the activities must be long enough to include the topic and give significant information, but short enough to not lose the attention of the children; if the event time is extensive enough, secondary information is given and the concepts learned are explored.

\subsection{Strategy development}

The learning of concepts is not the only objective while learning science and, usually, this is not motivating to students, the learning of sciences must have a significant learning with favorable conditions and cognitive structure. $^{3}$ Teaching must be part of students formation by including concepts, values and attitudes in a process where the student meet itself, the surroundings, ${ }^{4}$ and learn how to socialize.

As a first step of the strategy, the constructivism was used as main factor for the activities, as many authors stands, the learning is a process where the link between the experiences and ideas meet, moreover, the ideas must be linked ${ }^{5}$ to complete a knowledge of the world. In conclusion, the hands-on activities accomplish this philosophy. As a second step, the Active Learning of Optics (ALOP) philosophy was implemented on the handson activities, ${ }^{2}$ inspired in other successful works. ${ }^{5,6}$ To complete the strategy, the experiences must achieve a meaningful learning as stated by David Ausubel. On the other hand, demonstrations are focused on the concepts, and usually were not inexpensive because the main objective was to demonstrate a concept and link it with the hands-on activities.

\section{EVENT DESCRIPTIONS}

The Optics 4 every1 was a 1-year program to celebrate the IYL2015, in the next years the celebration will only be in 1 day to commemorate the IYL2015. The program consisted in 13 events where students and families learned about the IYL2015 and optics. The events will be described next.

\subsection{Week of light - Semana de la luz}

The opening event, the week of light was on the Facultad de Ciencias Fisico Matematicas from February $19^{t h}$ to $23^{\text {th }}$. This event was focused on general public, mainly faculty students, with the purpose of socialize and commemorate the begging of the IYL2015 in our city. It has activities that include a Goldberg machine, see Fig. 1 , where students were encouraged to socialize, use creativity and concepts to achieve a complex machine. The machine took 1 week to be constructed and the concepts applied were, mechanics, thermodynamic, pressure, magnetism with the purpose of light UV SPIE, Faculty, Universidad Autonoma de Nuevo Leon (UANL) and IYL2015 logos.
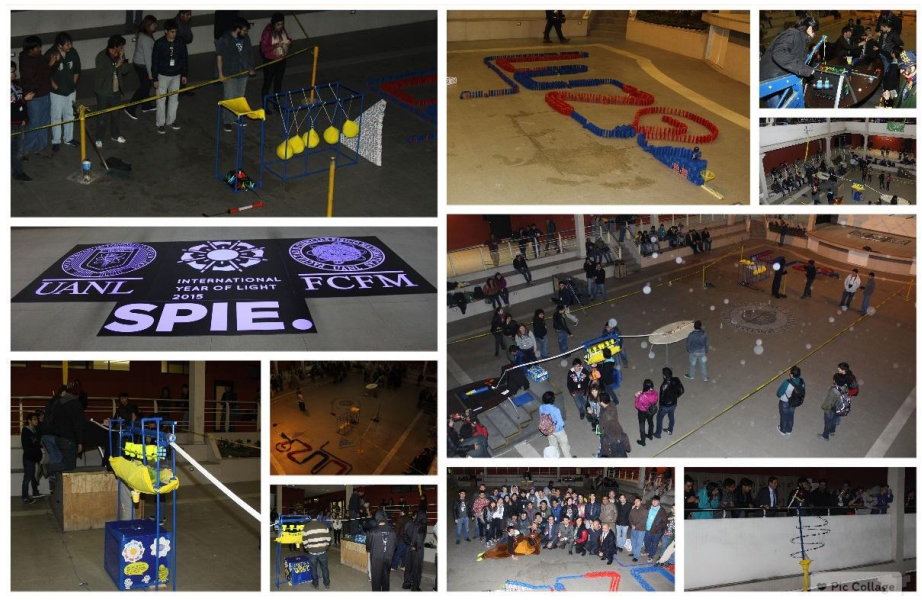

Figure 1. Goldberg Machine construction and activation for celebrate the IYL2015. 
Other activity was the Night with Light as shown in fig 2, it consisted in demonstrations, among them were the Tyndall effect, the electric field properties, phosphorescence and fluorescence properties and reflection properties, faculty students took the role of teachers and teach the concepts with the experiments provided.

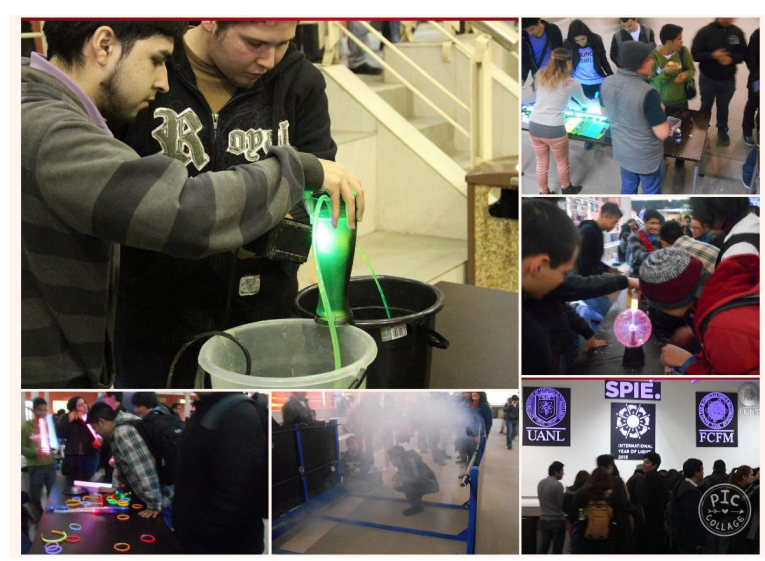

Figure 2. Night with Light. Open event at the Facultad de Ciencias Fisico Matematicas where college students, teachers, kids and general public participated on interactive demonstrations related with Optics.

\subsection{Optics demonstrations with High School students}

The high school Preparatoria 20 visited the Facultad de Ciencias Fisico Matematicas on February $20^{t h}$. This event was composed by optics demonstrations as the Fig. 3 show. The activities related in this event were:

- Khet challenge: a challenge using the Khet 2.0 laser game, this activity was used to explain the law of reflection and challenge students to complete with only pieces rotation a goal in the game (defeat the pharaoh). Teams of students socialized to achieve the goal.

- Strobe light effects: this activity uses a strobe light, which was used to show the movement of draws on a disk, the students were asked to explain the phenomena and they relate it with the concept of frequency.

- Moire pattern: this was used to show an optical effect of motion. This activity consists in the exploration of books with Moire patterns that show images movement. The main purpose was to contrast of strobe light effects movement, and again, a periodicity was implied.

- Plasma ball: this activity was more complex than the others, it demonstrates the effects of the electric field on gases, its main purpose is to give an experience on what electric field can achieve, this is usually an isolated concept and the students learn it with draws about the electromagnetic phenomenon.
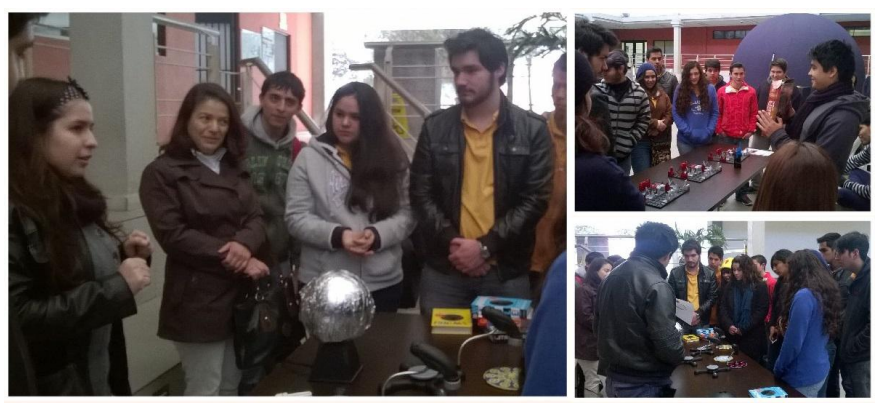

Figure 3. Optics demonstrations with high school students. 


\subsection{Visit to Elementary School Nuevo Colegio Israelita de Monterrey}

This event was held on the Elementary School Nuevo Colegio Israelita de Monterrey on March $24^{\text {th }}$. This event consisted on demonstrations and hands-on activities during their cultural week. The Fig 4 show the event. The hands-on activities were:

- Fake 3D: with a pattern in a paper, the students build a figure were they can see a cube if they use only 1 eye, this activity focus on the binocular vision and how it works.

- Fluorescence and Phosphorescence: usually these concepts are confused, in this activity the student manipulates materials given with UV light and learn about the difference. The students also experiment with other materials they carry, like cloths, paper or pencils.

- Tyndall effect: to demonstrate how a ray beam can be observed if it passes through smoke and relate the concept with clouds and particles in the atmosphere. In this activity the challenge is to pass through a laser maze and the students learn that at different angles, ray beams cannot be seen clearly.

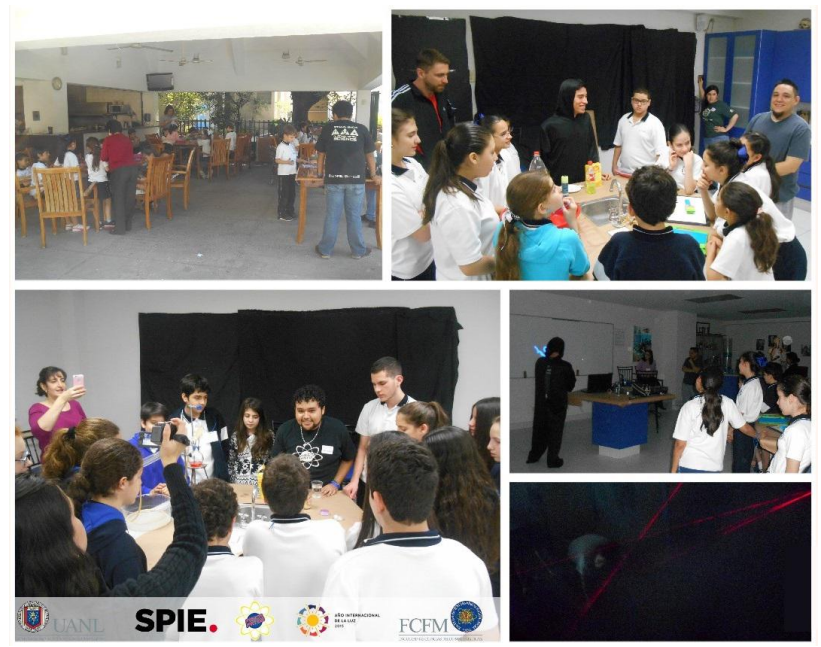

Figure 4. Celebrating the International Year of Light 2015 at the Nuevo Colegio Israelita de Monterrey. Optics demonstrations for basic education students with the purpose of learn about the importance of the IYL2015.

\subsection{Science in Family}

This event was on Facultad de Ciencias Fisico Matematicas on July $11^{t h}$. The activities were in support with the event Science in Family were families are gathered to learn about science. Due to diversity on ages this event includes experiments like the plasma ball, a kaleidoscope, a mirascope, a polarization kit. In the event, families come to a table full of experiments and ask how each one works as can be seen on Figure 5.

- Kaleidoscope: this activity is to learn about the reflection, usually focused on children due to its simplicity.

- Mirascope: this activity is to learn about the reflection on concave mirrors, the students see how an image is formed and then asked how is formed.

- Polarization Kit: this is a complex activity about light, the polarization usually is not included in elementary school, but in this case, it was included to challenge older students. During this activity

- Colors: in this activity the IYL2015 light blox was used. 


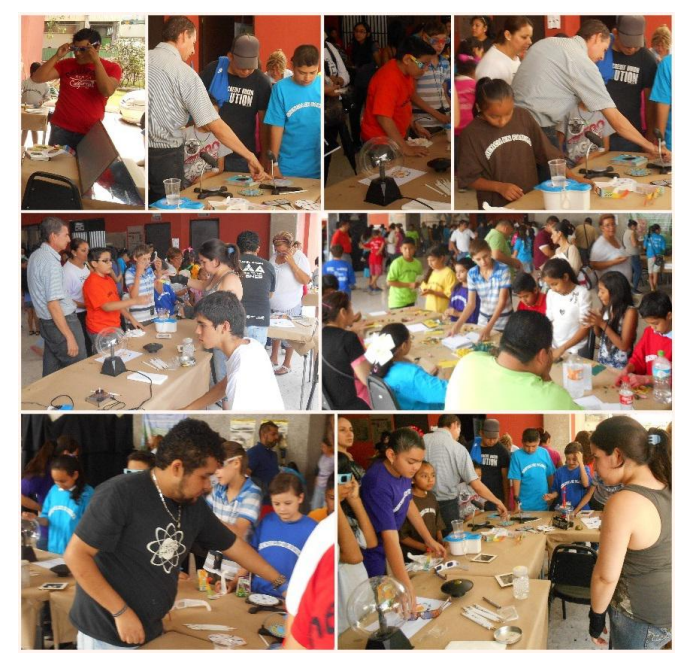

Figure 5. Science in family 2015. Event organized by the Education Secretary in the Nuevo Leon state. The group "Physics for everyone" presented different demonstration related with Optics.

\subsection{Summer Camp Little Bisons}

The summer camp Bisontitos or Little Bisons is held each year at Facultad de Ciencias Fisico Matematicas on July and is 2 weeks long. During this event, several hands-on experiments and demonstrations were shown to kids from 6 to 14 years old, due to the time of each lab class (40 minutes) the experiences in this event were huge. The activities included color, fluorescence and phosphorescence. In this event, the color activity was longer than the past events, it included the IYL2015 diffraction gratings were the students use the gratings to see different color lights and even fire as the Figure 6 shows, one interesting phenomenon is when a laser light is shown, this particular experience demonstrate the difference between light and laser light. Also, a particular activity was included, in the color activity a stereoscopic diffraction lenses were included, the objective was an experience were the students draw in a black paper and make their own 3D draws with warm colors on the bottom and cold colors on front. In addition, during the class the difference about phosphorescence, fluorescence and chemiluminescence was explained and, later, during the night closing event, the kids enjoyed a black-theater performance.

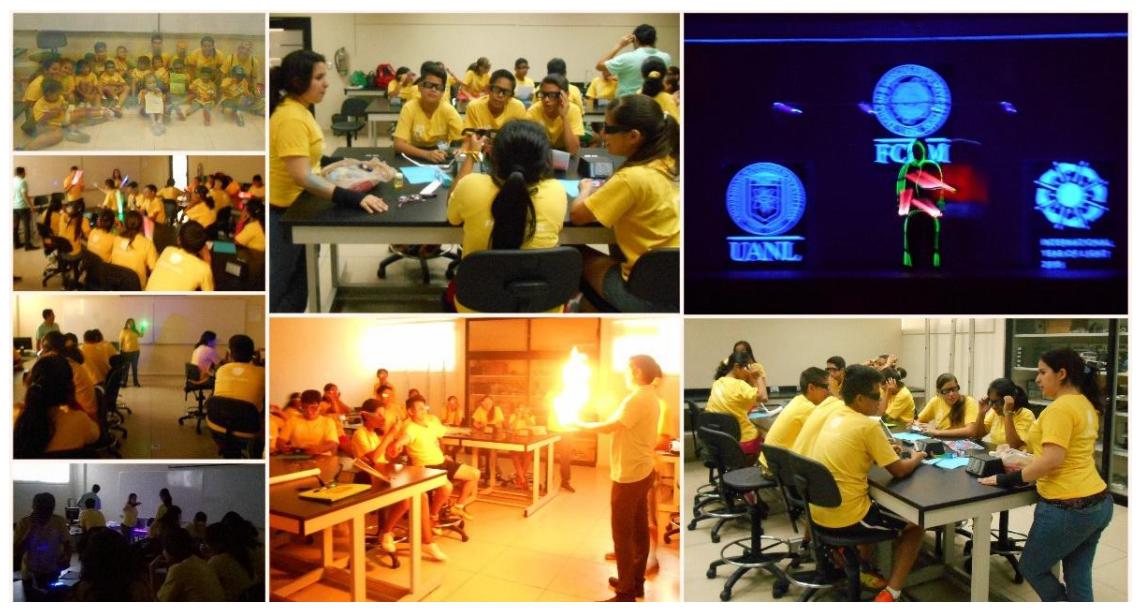

Figure 6. Optics outreach activity during the summer camp "Little Bisons". During the summer camps the kids and teenagers done hands-on activities related with color and light phenomena. In addition, they enjoyed of one black-theater performance. 


\subsection{Woman in Science}

The program Woman in Science is a University program were high school students visit the university research centers. This event was on September $25^{\text {th }}$ and October $2^{\text {nd }}$. The activities in this event included the mirascope, colors and plasma ball. In addition, lenses were shown and explained to students.

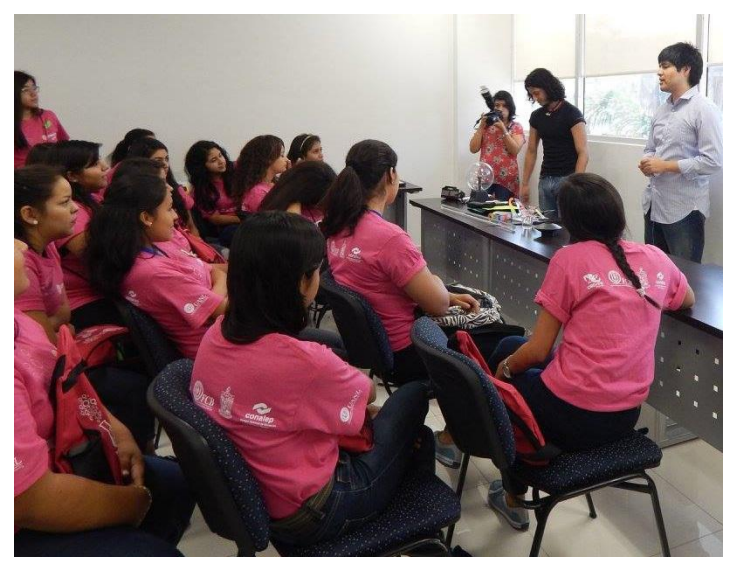

Figure 7. Women in Science UANL. Hands-on activities related with Optics and its application in daily life.

\subsection{Book Fair}

On October $16^{\text {th }}$, the Monterrey book fair is held at the Convention Center Cintermex. During this event, the celebration of IYL was shown with the "Light: beyond the bulb" exhibit and a day of demonstrations to elementary school students. In this event, several schools visited the convention center making time limit activities. Strobe light effects, a kaleidoscope, colors and plasma ball activities were included.

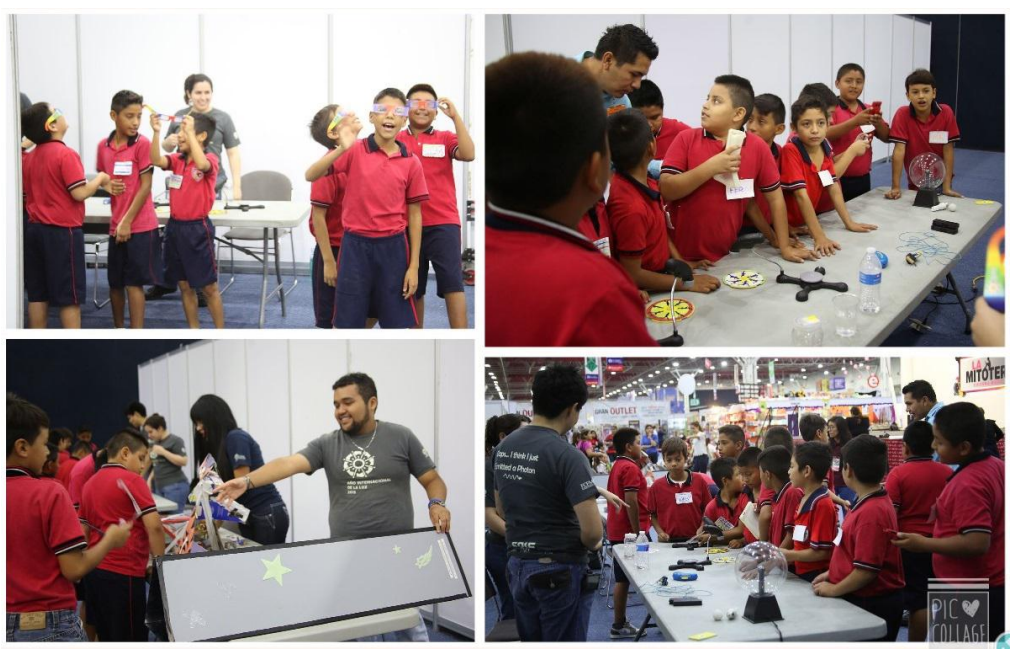

Figure 8. Optics demonstrations at the International Book Fair Monterrey 2015.

\subsection{Week of Science}

The Week of Science is a national event of the Consejo Nacional de Ciencia y Tecnologia (National Council of Science and Technology, CONACyT) were Universities and Research Centers in Mexico held simultaneous Science outreach events, it was from October $19^{\text {th }}$ to $22^{\text {th }}$. The program participation on this week was with quick demonstrations of no more than 30 minutes. The activities included a plasma ball, a kaleidoscope, strobe 
light effects and colors. During this particular event a light ball that separate the colors and gel balls were included. The Figure 9 show a picture of the students presenting the experiments.

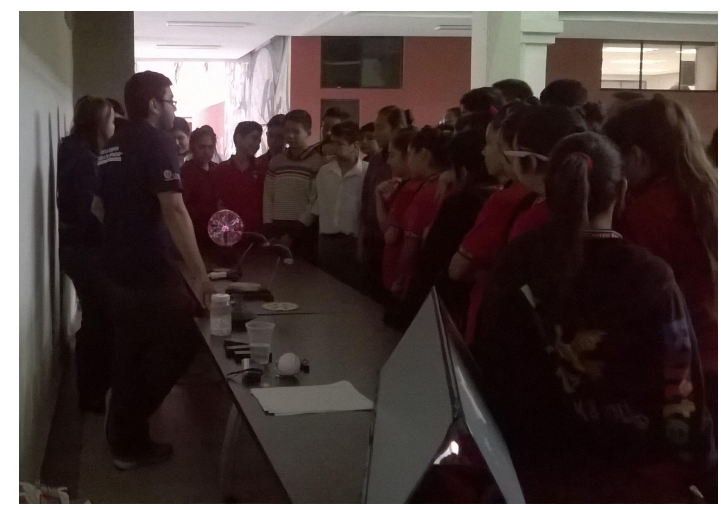

Figure 9. Optics demonstrations at National Week of Science and Technology 2015.

\subsection{Instituto Tecnologico of Ciudad Victoria Visit}

Bachelor students from the Technological Institute of Ciudad Victoria City visited the Faculty facilities on October $27^{\text {th }}$. During this event, activities like the plasma ball, strobe light effects, IYL2015 diffraction grating lenses and light blox were shown. In addition, during the light blox activity, acrylic lenses and laser lights were shown to replicate the light blox lenses, so students can try the different lens configurations. The figure 10 show pictures of this event.

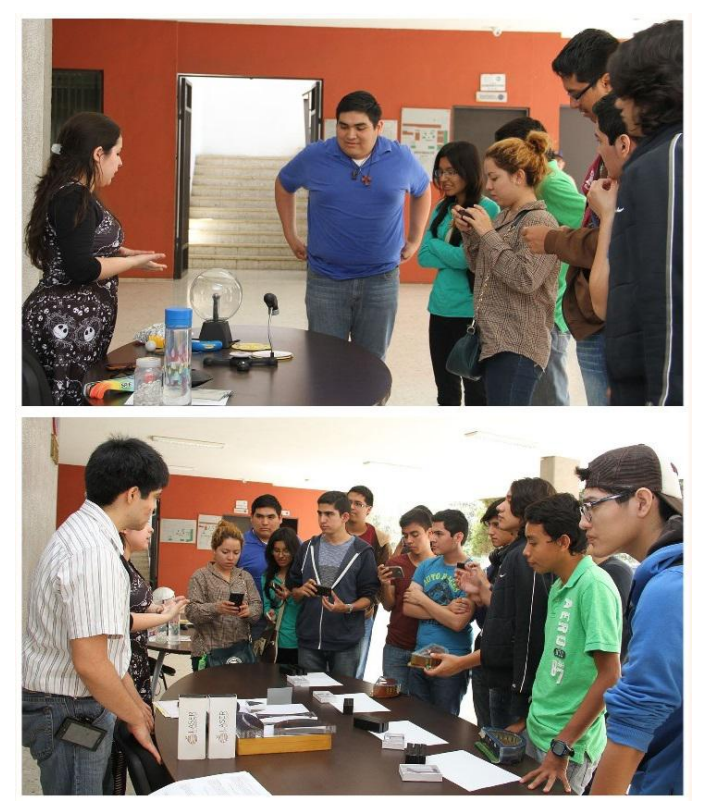

Figure 10. Hands-on activities with bachelor students from the Instituto Tecnologico de Ciudad Victoria.

\subsection{Visit to Elementary School Vicente Guerrero}

On November $12^{\text {th }}$, the Astronomy club and the "Physics 4 every1" group visited the Elementary School Vicente Guerrero. During this event, activities like the plasma ball, IYL2015 diffraction grating lenses, color, a mirascope and a kaleidoscope were shown. Figure 11 show pictures of this event. 

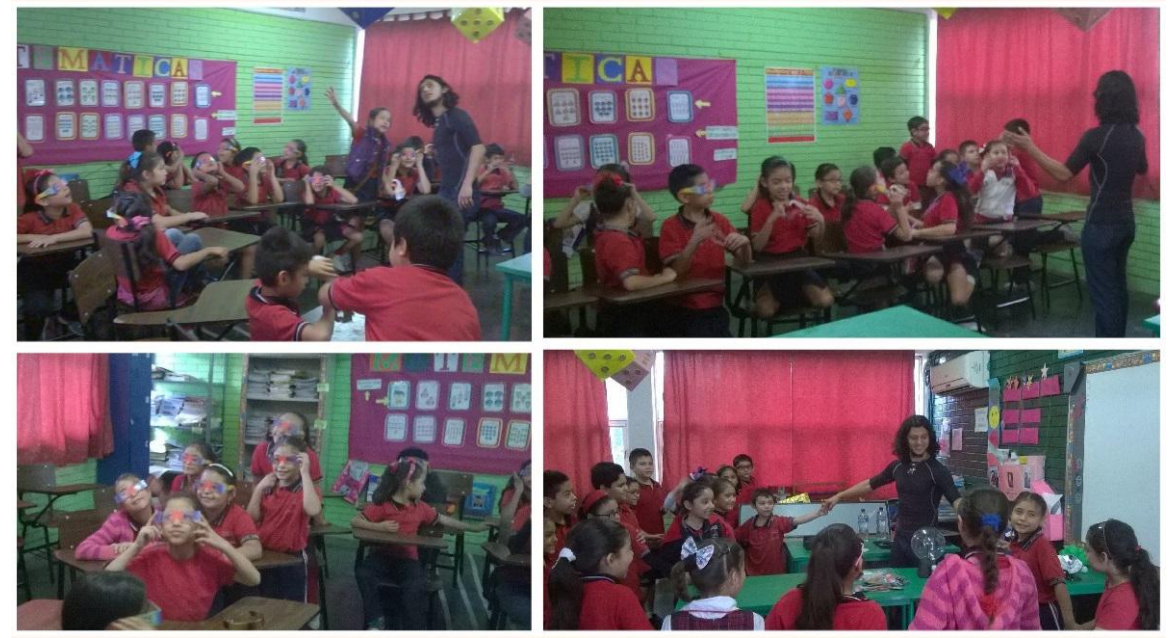

Figure 11. Hands-on activities about color, light, 3D and perception at the Elementary school Vicente Guerrero.

\subsection{Colegio Ingles Americano visit}

On November $13^{\text {th }}$, the Colegio Ingles Americano visited Facultad de Ciencias Fisico Matematicas. During this event, activities like color, plasma ball, IYL2015 diffraction gratings lenses were shown as the Figure 12 show. During this event, the static electricity was linked with the plasma ball with a particular activity, stick a balloon to a wall with static electricity.

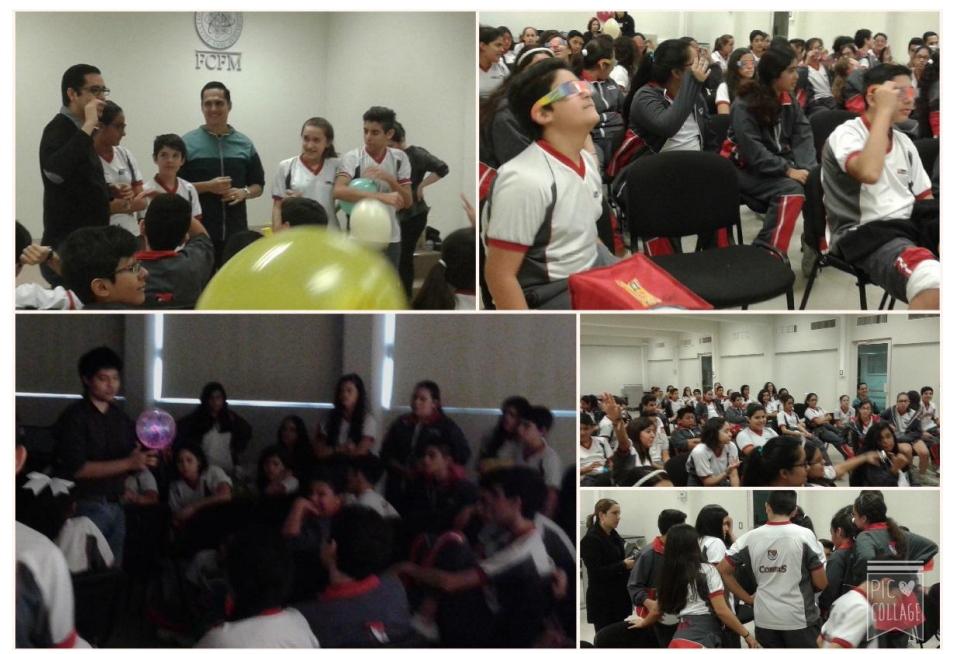

Figure 12. Hands-on activities about color and light during the visit of the Collage Ingles Americano at the FCFM facilities.

\subsection{Optica Pato2 FCFM}

The Optica Pato2 FCFM is a yearly event, in 2015 was on November $18^{\text {th }}$. This event reunites all the activities shown before and the mobile planetarium of the Astronomy club. This event includes activities like the Tyndall effect, the plasma ball, color, light blox, Moire pattern books, stereoscopic diffraction lenses, strobe light effect, fluorescence and phosphorescence, IYL2015 diffraction grating lenses, acrylic lenses and binocular vision. The activities make a complete experience about light to commemorate the IYL2015. Figure 13 and 14 show the event pictures. 


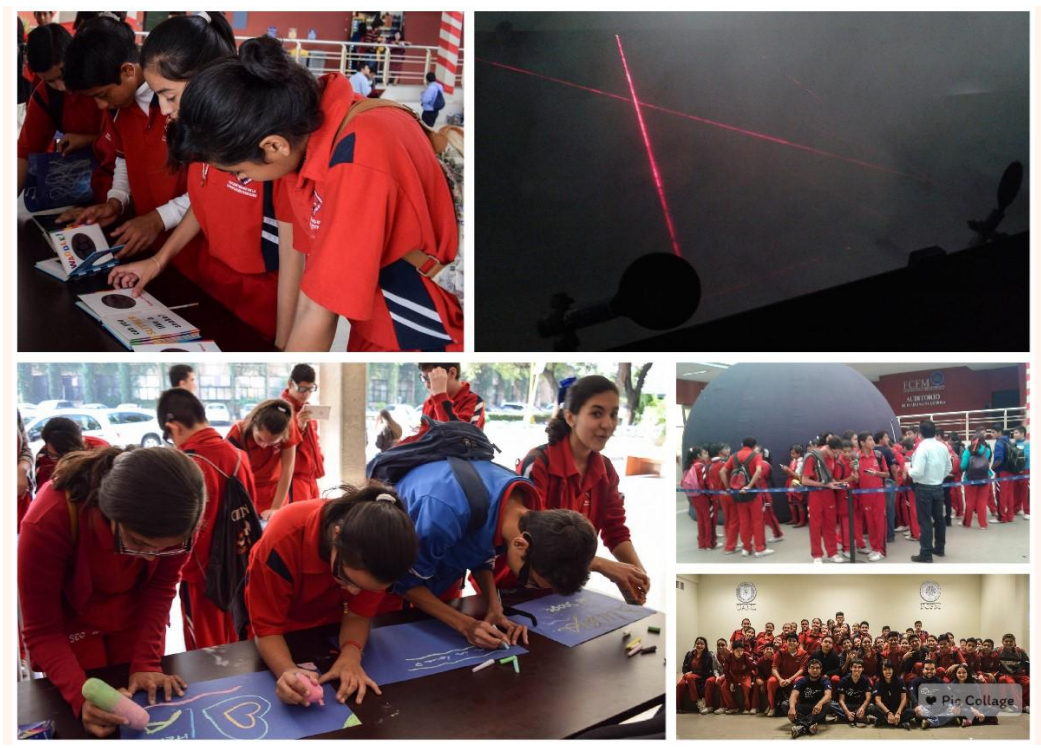

Figure 13. Hands-on activities about light, 3D, perception, laser safety and light phenomena during the event "Optica Pato2 2015" at the FCFM facilities.
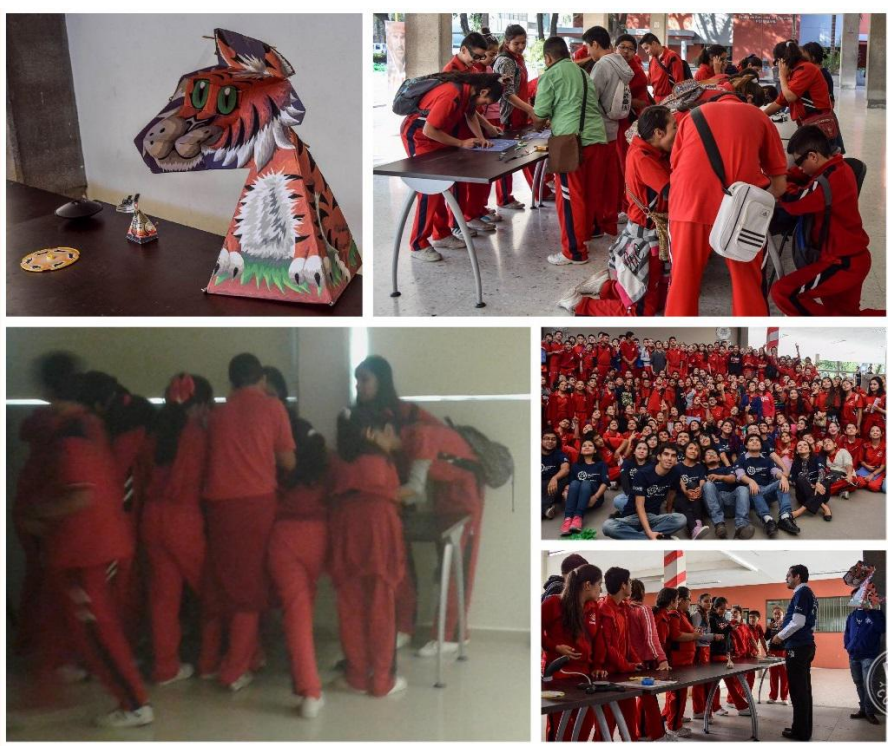

Figure 14. Hands-on activities about optical illusions, waves and light phenomena during the event "Optica Pato2 2015" at the FCFM facilities

\subsection{Night with the Stars}

On November $28^{t h}$, the International Event Night with Stars was held on Monterrey, Mexico. During this event the participation of the program was with activities like the plasma ball, IYL2015 diffraction grating lenses, binocular vision, kaleidoscope and color. Figure 15 show pictures of the event were children and adults assisted.

\section{RESULTS}

The activities changed along the year with the comments of students, parents and teachers, this feedback make possible the integration of teaching kits for different phenomena, also one part of the feedback was the assistant reaction: kids, youth and adults were amazed by the activities. 

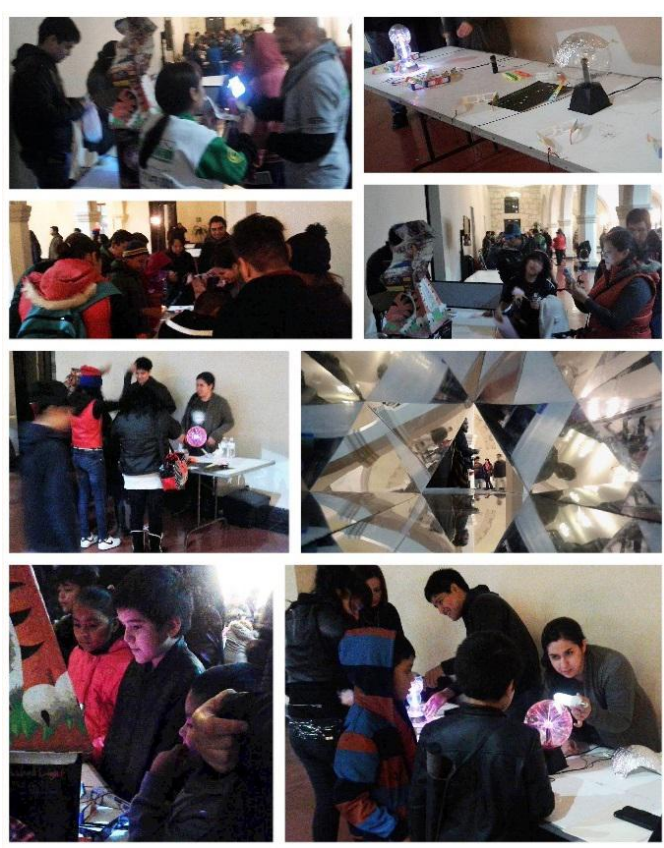

Figure 15. Science demonstrations about optical illusions, waves, 3D and light phenomena during the event "Night with the Stars" at the UANL facilities.

Looking for achieve a better understanding of the activities shown, it was necessary apply modifications with every event, public, activity and topic. The more complex activities were left to higher education levels.

With every event several questions were made by the assistants, this was also a feedback for improve our labor for future events.

In summary, thanks to the aforementioned events, more than 8,000 people were reached including not only kids, teenagers and basic education teachers, also parents and general public, who were interested in learn more about the world where we live and about the importance of the Light and its importance in our daily life.

\section{CONCLUSIONS}

These events were important to complement the local education, because the activities are ideal to link concepts with experiments. Teachers were interested on the activities and wanted to replicate in the school, but the lack of information about where to find materials like diffraction grating make it hard to replicate, this is where education kits fulfill this need.

The objectives of the International Year of Light were present in the program, and the events celebrated the IYL2015. Along the year, a lot of teachers were reached and they frequently ask for events in schools, this kind of feedback can make this program be permanent and in continuous renovation. In addition, the presentation of kits will continue to encourage teachers to experiment in class.

\section{ACKNOWLEDGMENTS}

The group "Physics 4 every1" and its program "Optics 4 every1" were possible thanks to the support of the International Society for Optics and Photonics and the Universidad Autonoma de Nuevo Leon through the Facultad de Ciencias Fisico Matematicas.

All the events described above were enriched by activities of the Astronomy Club and the Robotic Club of the FCFM. 


\section{REFERENCES}

[1] Ruiz-Mendoza, J., Alternativa metodológica para la formación integral de los estudiantes desde el proceso de enseñanza de la Física, PhD thesis, Universidad de Camagüey (2005).

[2] Alarcon, M., Ben Lakhdar, Z., Culaba, I., Lahmar, S., Lakshminarayanan, V., Mazzolini, A. P., Maquiling, J., and Niemela, J., "Active learning in optics and photonics (ALOP): a model for teacher training and professional development," 7783, 778303-778303-8 (aug 2010).

[3] Gagné, R. M., Ausubel, D. P., and Gagne, R. M., "Educational Psychology: A Cognitive View," American Educational Research Journal 6, 287 (mar 1969).

[4] Torres, A., Ruíz, J. C., and Alvarez, N., "La autotransformación del estudiante universitario : más allá de la formación integral," Revista Iberoamericana de Educación 43, 2-9 (2007).

[5] Arango, C. M. G., "La enseñanza de la óptica desde una conceptualización integradora de sus teorías, dinamizada y orientada por una concepción del aprendizaje significativo crítico," documento de trabajo, Universidad Nacional de Colombia, Medellín, Medellín (2013).

[6] Marín, D. P. V., "Estudio del impacto didáctico de la metodología "de aprendizaje activo" en la enseñanza de la óptica," documento de trabajo, Universidad Nacional de Colombia, Sede Medellín (Junio 2012). 